\title{
Efficacy of pembrolizumab combined with anlotinib in 3 patients with advanced non- small cell lung cancer
}

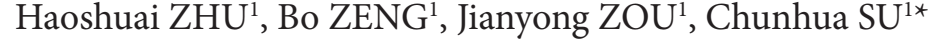

\begin{abstract}
Non-small-cell lung carcinoma (NSCLC) is any type of epithelial lung cancer and accounts for about $85 \%$ of all lung cancers. Pembrolizumab, a PD-1 inhibitor, is approved to treat patients with advanced NSCLC. Anlotinib, a multi-target tyrosine kinase inhibitor, is approved in China for treating patients with advanced NSCLC with progression or recurrence after $\geq 2$ lines of systemic chemotherapy. Whether pembrolizumab combined with anlotinib has synergistic effects on treating advanced NSCLC patients remains unclear. Here we reported that three cases of patients with advanced NSCLC had a good response and a long time of PR to pembrolizumab combined with anlotinib treatment, indicating that combined administration of pembrolizumab and anlotinib can be optional management for advanced NSCLC.
\end{abstract}

Keywords: Non-small-cell lung carcinoma (NSCLC); pembrolizumab; anlotinib.

Practical Application: pembrolizumab combined with anlotinib may be a better choice for patients with advanced NSCLC.

\section{Introduction}

Non-small cell lung cancer is the leading cause of cancerrelated deaths worldwide and is often diagnosed with a poor prognosis (Siegel et al., 2017). Immunotherapy in combination with chemotherapy is recommended to treat patients with stage IV NSCLC without driver alteration (Hanna et al., 2020). Also, there is a potential future perspective of immunotherapy combined with anti-angiogenic agents for treating advanced NSCLC (Liang \& Wang 2019). Some evidence suggests that angiogenesis may be associated with immunosuppression in the tumor microenvironment (TME), thereby enhancing the immune escape of tumor cells (Ohm \& Carbone 2001). The key strategy for targeting TME is to inhibit angiogenesis and stimulate an effective immune response. Anti-angiogenic agents can stimulate the immune system, and immunotherapy might also exert an anti-angiogenic effect. A combination of these agents might produce synergistic effects on treating tumors (Garber 2014).

Pembrolizumab is a human IgG4 mAb against PD-1. Based on a series of clinical trials, pembrolizumab was approved to treat patients with advanced non-squamous or squamous NSCLC (Hanna et al., 2020). Anlotinib has presented an inhibitory effect on tumor growth and angiogenesis by inhibiting multiple targets such as VEGFR, PDGFR, FGFR, and c-Kit (Lin et al., 2018). Phase III ALTER 0303 trial showed that anlotinib can significantly prolong the OS and PFS in patients with advanced NSCLC (Han et al. 2018a).

However, currently, there was no report on the effects of combined administration of pembrolizumab and anlotinib on treating patients with advanced NSCLC as yet. Here we report three cases with advanced NSCLC who received a satisfactory response to pembrolizumab combined with anlotinib.

\section{Case description}

\subsection{Case 1}

A 70-year-old male diagnosed with lung cancer at left low lobe (cT2N0M0 IB) received radical resection with left low lobe dissection and mediastinal lymphadenectomy in March 2018. The pathology revealed acinar adenocarcinoma with a pathological stage of IB (pT2N0M0, tumor size $4^{\star} 3^{\star} 3 \mathrm{~cm}^{3}$ ) and R0 resection. Tumor tissues were collected and sent to the pathological department for next-generation sequencing (NGS) cancer gene panel (13 genes) detection which showed a mutation of PIK3CA ES45 without other gene mutations. Histochemistry test for PD-L1 in tumor tissue showed a positive rate of $20 \%$. Regular follow-ups were performed to monitor the disease progression after four cycles of adjuvant chemotherapy. Patients complained of paralysis in left upper and low limbs on Aug 2, 2019. Oncology Group performance status (ECOG PS) scores were 2. PET and brain MRI showed a $16 \mathrm{~mm}^{\star} 15 \mathrm{~mm}$ nodule in the left upper lobe of the lung and a $24 \mathrm{~mm}^{\star} 33 \mathrm{~mm}^{\star} 28 \mathrm{~mm}$ mass in the right frontal lobe of the brain (Figure $1 \mathrm{A1}, 2$ ). The disease-free survival (DFS) was recorded as 16 months. Surgery resection of the two metastases combined with chemotherapy was considered as the first suggestion and the second suggestion in terms of synchronous radical radiotherapy (focused on the two metastases in lung and brain) and chemotherapy were both rejected by the patient and kinsfolk.

With full informed consent, the patients were administered with pembrolizumab $(200 \mathrm{mg}, \mathrm{q} 3 \mathrm{w})$ in combination with anlotinib (12 mg, D1-14, q3w) starting from August 5, 2019. Ten days later, the patient recovered from left upper and low limb paralysis with an ECOG PS scores of 0-1. Chest CT and brain MRI after 2 months revealed an SD. The most recent PET and brain MRI 


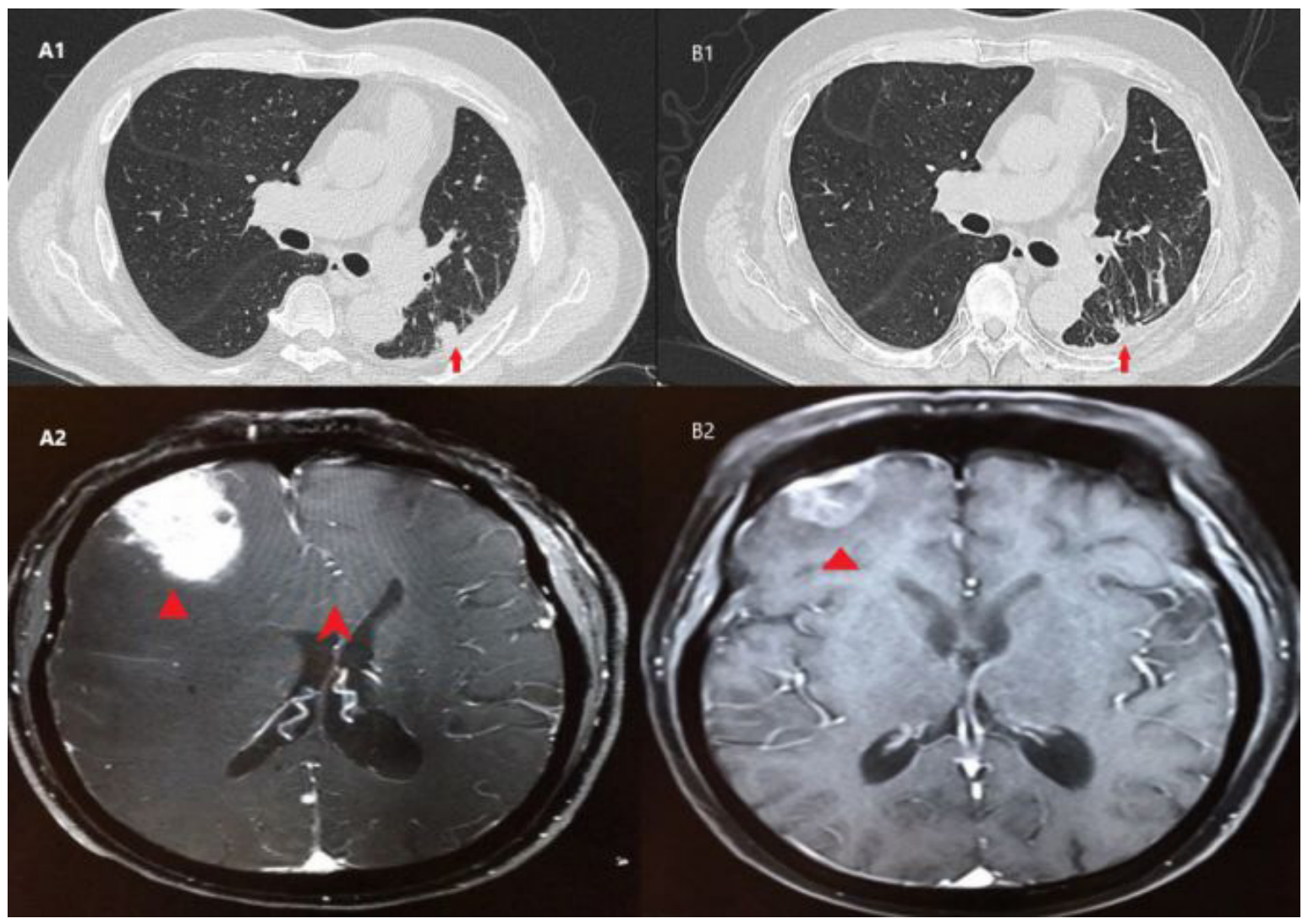

Figure 1. A1: PET on Aug 2, 2019, showed a $16 \mathrm{~mm}^{\star} 15 \mathrm{~mm}$ metastatic nodule in the left upper lobe of the lung, and A2: brain MRI showed a $24 \mathrm{~mm}^{\star} 33 \mathrm{~mm}^{\star} 28 \mathrm{~mm}$ metastatic mass in the right frontal lobe of the brain. PET and brain MRI at March 31, 2020, revealed an outcome of PR with a $15 \mathrm{~mm}^{\star} 12 \mathrm{~mm}$ nodule in the left upper lobe of the lung (B1) and a $21 \mathrm{~mm}^{\star} 14 \mathrm{~mm}^{\star} 16 \mathrm{~mm}$ mass in the right frontal lobe of the brain (B2).

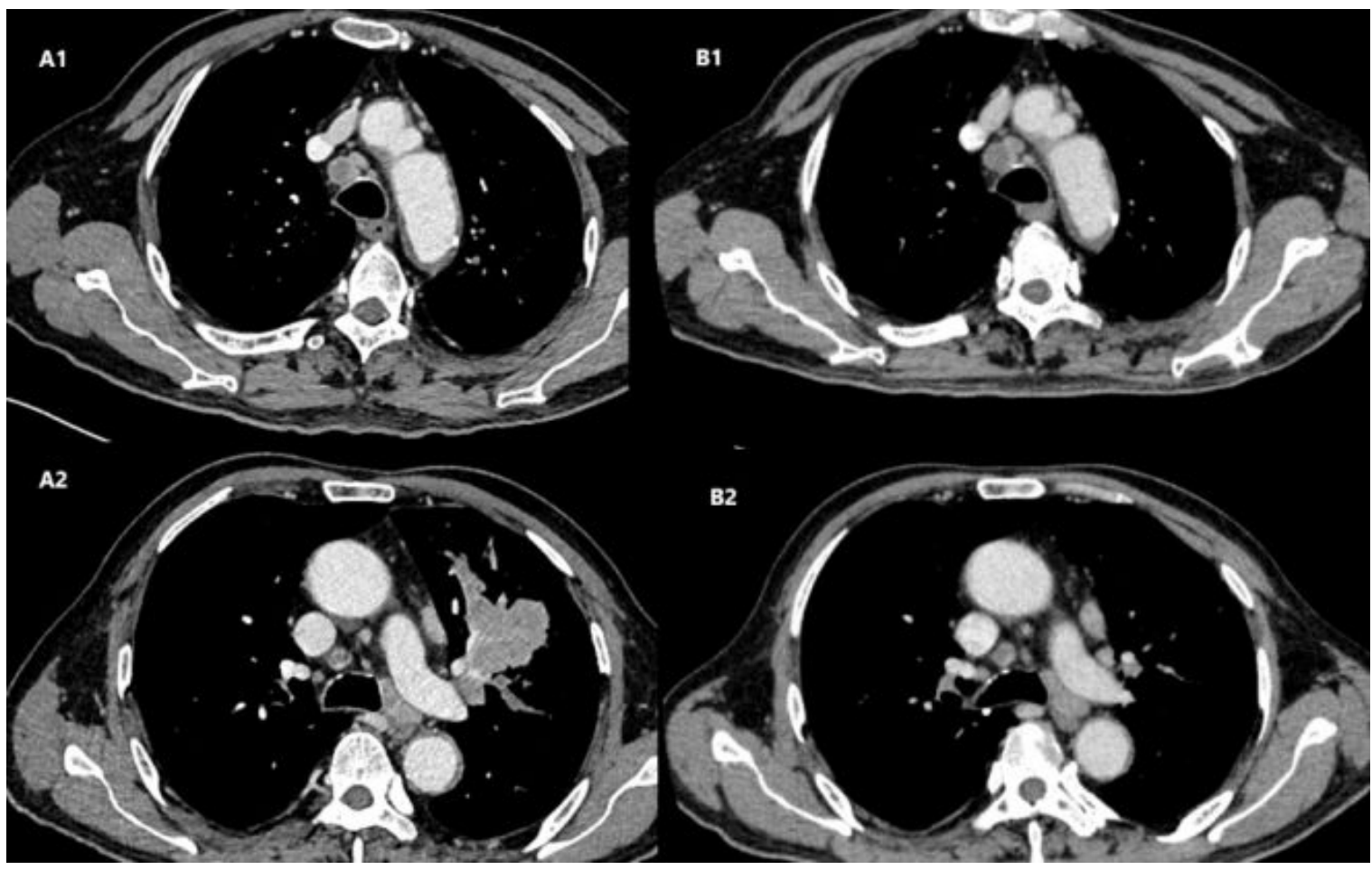

Figure 2. Chest contrast CT on July 19, 2019, showed a $4.6 \mathrm{~cm}^{\star} 3.4 \mathrm{~cm} * 3.2 \mathrm{~cm}$ mass in the left upper lobe of the lung and multiple enlarged lymph nodes in the mediastinum and bilateral hilum of the lung $(\mathbf{A 1}, 2)$. Chest CT on Feb 14, 2020, showed an outcome of PR with the left upper mass nearly disappeared (B2) and stable in lymph nodes (B1). 
on March 31, 2020, revealed a PR with a $15 \mathrm{~mm}^{\star} 12 \mathrm{~mm}$ nodule in the left upper lobe of the lung and a $21 \mathrm{~mm}^{\star} 14 \mathrm{~mm}^{\star} 16 \mathrm{~mm}$ mass in the right frontal lobe on the brain (Figure $1 \mathrm{~B} 1,2)$. The ECOG PS scores were 0 . The patients showed good tolerance with no adverse events during the treatment period. Up to now (nearly 9 months), the patient was still in PR.

\subsection{Case 2}

A 73-year-old male complained of cough and bloody sputum. Chest contrast CT and brain MRI on July 19, 2019, showed a $4.6 \mathrm{~cm}^{\star} 3.4 \mathrm{~cm}^{\star} 3.2 \mathrm{~cm}$ mass (SUVmax 12.1) in the left upper lobe of the lung and multiple enlarged lymph nodes in the mediastinum and bilateral hilum of the lung (Figure $2 \mathrm{A1}, 2$ ). Biopsy by E-BUS from left upper lobe focus and enlarged lymph nodes confirmed the pathology of low moderately differentiated squamous carcinoma with clinical staging of IIIB (cT2N3M0). ECOG PS scores were 0. Biopsy specimens were sent to the pathological department for NGS cancer gene panel ( 575 genes) test with the results showing clinically significant gene mutation in TP53, PIK3CA, and FGFR1. Histochemistry test for PD-L1 in tumor tissue showed a positive rate of $30 \%$. The patients and his kinsfolk rejected synchronous radical radiotherapy and chemotherapy which we recommended.

With full informed consent, the patients were administered with pembrolizumab (200 $\mathrm{mg}, \mathrm{q} 3 \mathrm{w})$ in combination with anlotinib (12 mg, D1-14, q3w) starting from July 25, 2019. Chest CT or PET every 2 months after treatment was applied to assess disease progression. The recent chest CT on Feb 14, 2020 , showed an outcome of PR with left upper lobe mass nearly disappeared (Figure 2 B2) and stable in lymph nodes (Figure 2 B1). The ECOG PS was 0 and no bloody sputum was complained. Adverse events of diarrhea and pruritus were observed in this patient but could be controlled by symptomatic treatment. Up to now, the patient was still in PR.

\subsection{Case 3}

A 50-year-old male complained of cough and dyspnea. A chest X-ray showed a mass in the right upper lung. PET and brain MRI on November 22, 2018, showed a solid mass of $93 \mathrm{~mm}^{\star} 82 \mathrm{~mm}^{\star} 76 \mathrm{~mm}$ in the right upper lobe of the lung and fusion lymph nodes in the right hilum $\left(56 \mathrm{~mm}^{\star} 42 \mathrm{~mm}\right)$ of the lung and mediastinum (Figure 3 A1,2). Biopsy by E-BUS from right upper lobe mass and enlarged lymph nodes confirmed the pathology of low moderately differentiated adenocarcinoma with clinical staging of IIIB (cT4N2M0). ECOG PS scores were 1. Biopsy specimens were sent to the pathological department for NGS cancer gene panel (13 genes) test which showed a gene mutation in KRAS G12C. Histochemistry test for PD-L1 in tumor tissue showed a positive rate of $90 \%$. Pemetrexed combined with nedaplatin and bevacizumab was administered for 6 courses starting from December 5, 2018, with an outcome of PR (a cystic-solid mass of $46 \mathrm{~mm}^{\star} 40 \mathrm{~mm}^{\star} 43 \mathrm{~mm}$ in the right upper lobe of the lung and stable fusion lymph nodes on June 15, 2019) (Figure 3 B1). Another four courses of maintenance chemotherapy with pemetrexed combined with bevacizumab were administered with an outcome of SD. Three months after chemotherapy, the patient complained of back pain. PET on
October 8, 2019, showed bone metastasis in the fourth thoracic vertebra (SUVmax 11.5) and metastasis in S4 of the liver (B2), and stable of the right upper focus.

With full informed consent, the patients were administered with pembrolizumab (200 $\mathrm{mg}, \mathrm{q} 3 \mathrm{w})$ in combination with anlotinib (12 mg, D1-14, q3w) starting from October 17, 2019. PET on December 23, 2019, showed that the metastasis in S4 of the liver disappeared (Figure $3 \mathrm{C} 2$ ), the SUVmax decreased in the thoracic vertebra metastasis and the main focus and lymph nodes were stable. An SD was obtained. The most recent PET on March 10, 2020, showed a PR with a decrease in size with $3.5 \mathrm{~cm}^{\star} 2.5 \mathrm{~cm}^{\star} 2.7 \mathrm{~cm}$ of fusion lymph nodes in the right hilum (Figure $3 \mathrm{C} 1$ ). Adverse events of hypertension were observed but could be controlled by united hypotensive drugs.

\section{Discussion}

This is the first report of patients with advanced NSCLC showing a good response to the combined treatment with pembrolizumab and anlotinib. Anlotinib can inhibit substrate phosphorylation and signal transduction by competing with ATP for binding sites on VEGFR/PDGFR/FGFR/c-kit, therefore exhibiting an effect of inhibiting tumor angiogenesis and tumor growth (Lin et al., 2018). Phase III ALTER 0303 trial evaluated the efficacy and safety of anlotinib in patients with advanced NSCLC. Results showed that anlotinib can significantly prolong the OS (9.6 months vs 6.3 months; HR 0.68; 95\% CI 0.54-0.87; P = 0.002) and PFS (5.4 months vs 1.4 months; HR 0.25; 95\% CI 0.19- 0.31; $\mathrm{P}<0.001$ ) compared with placebo treatment (Han et al.2018a). Anlotinib as a third-line treatment provided significant PFS benefits ( 4.8 vs 1.2 months; hazard ratio $(\mathrm{HR})=0.32 ; 95 \%$ confidence interval $(\mathrm{CI}), 0.20-0.51 ; \mathrm{P}<0.0001)$ to patients with refractory advanced NSCLC compared with placebo (Han et al., 2018 b). What's more, anlotinib played a significant role in the salvage treatment of advanced NSCLC after at least two lines of chemotherapy (Wu et al., 2019).

On the evidence of Keynote 010, for patients with previously treated, PD-L1 positive, advanced NSCLC, pembrolizumab $10 \mathrm{mg} / \mathrm{kg}$ significantly improved both OS and PFS compared with docetaxel (Herbst et al., 2016). Keynote 024 found that in patients with previously untreated advanced NSCLC with PD-L1 expression on at least $50 \%$ of tumor cells and without EGFR or ALK alterations, pembrolizumab monotherapy was associated with significantly longer PFS and longer OS over platinum-based chemotherapy (Reck et al., 2016). Furthermore, Keynote 042 suggested that pembrolizumab monotherapy significantly prolonged OS in patients with advanced NSCLC with PD-L1 expression on at least 1\% of tumor cells (Mok et al., 2019). Keynote 189 (Gandhi et al., 2018) and Keynote 407 (Paz-Ares et al., 2018) demonstrated that the combination of pembrolizumab and a platinum-based drug standard chemotherapy significantly prolonged PFS and OS over chemotherapy alone in patients with first-line treatment metastatic non-squamous or squamous NSCLC.

A previous study reported a case with advanced metastatic esophageal squamous cell carcinoma who had CR in metastases to the combined treatment with nivolumab and anlotinib 


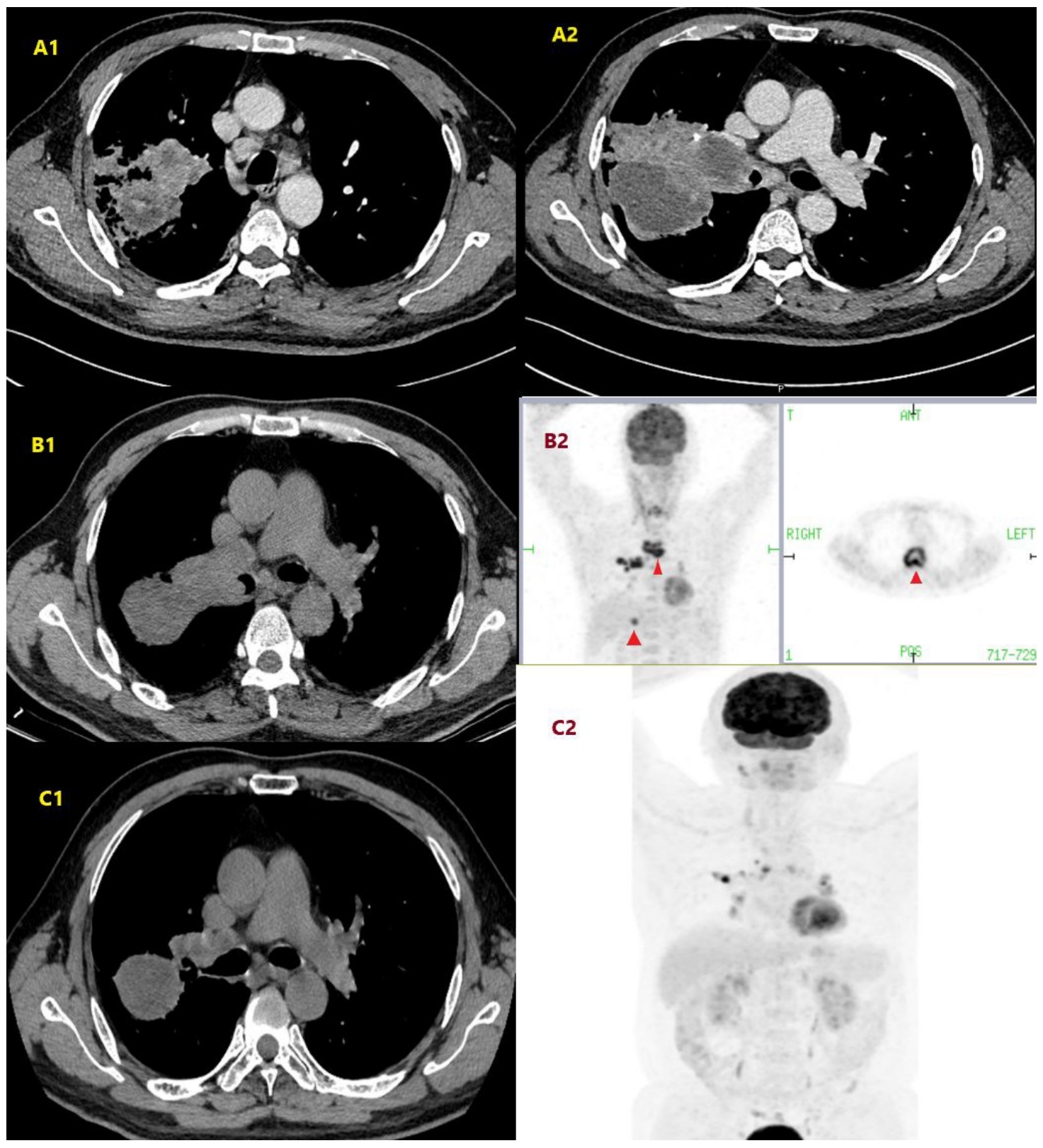

Figure 3. PET on November 22, 2018, showed a solid mass of $93 \mathrm{~mm}^{\star} 82 \mathrm{~mm} * 76 \mathrm{~mm}$ in the right upper lobe of the lung (A1) and fusion lymph nodes in the right hilum $\left(56 \mathrm{~mm}^{\star} 42 \mathrm{~mm}\right.$ ) of the lung and mediastinum (A2); PET on June 15, 2019, showed a cystic-solid mass of $46 \mathrm{~mm}^{\star} 40 \mathrm{~mm}^{\star} 43 \mathrm{~mm}$ in the right upper lobe of the lung and stable fusion lymph nodes (B1); PET on October 8, 2019, showed bone metastasis in the fourth thoracic vertebra (SUVmax 11.5) and metastasis in S4 of the liver (B2); PET on December 23, 2019, showed that the metastasis in S4 of liver disappeared (C2), the SUVmax decreased in the thoracic vertebra metastasis; PET on March 10, 2020, showed a PR with a decrease in size with $3.5 \mathrm{~cm}^{\star} 2.5 \mathrm{~cm}^{\star} 2.7 \mathrm{~cm}$ of fusion lymph nodes in the right hilum (C1).

(Tang et al., 2019). According to IMpower150, atezolizumab combined with bevacizumab, paclitaxel, and carboplatin showed a significant PFS benefit in non-squamous NSCLC patients when compared with the combination of bevacizumab, paclitaxel, and carboplatin. However, there was no difference in the response rate between atezolizumab + paclitaxel + carboplatin group and bevacizumab + paclitaxel + carboplatin group. These findings suggest that the anti-angiogenic drug (bevacizumab) has an immunomodulatory effect and can enhance the immune efficacy of atezolizumab (Socinski et al., 2018). Recently, the investigators are focusing on using immunotherapy as a basic therapy in combination with other treatment strategies (such as radiotherapy, chemotherapy, and targeted drugs), which have been thought to increase tumor-related immunogenicity by inducing tumor cell death and new antigen release (Liang \& Wang 2019). There was no clinical trial focused on the combined treatment of immunotherapy with anlotinib so far.

Approximately $35 \%$ of patients with metastatic NSCLC develop metastases to the brain, which is associated with poor prognosis (Gibson et al., 2018). Pooled analysis of Keynote 
021,189 and 407 showed that pembrolizumab plus platinumbased chemotherapy improved outcomes over chemotherapy alone in advanced NSCLC patients with brain metastases. Also, post hoc analysis of phase III randomized control trial (ALTER 0303) revealed anlotinib had activity in the brain and played a potential role in tumor control at intracranial sites (Jiang et al., 2020). Pembrolizumab combined with anlotinib benefited the three patients with a manageable safety profile. What's more, anlotinib improved quality of life compared with placebo in advanced NSCLC patients who had received at least two previous chemotherapies (Si et al., 2018).

In conclusion, the good response in the three patients after treatment with a combination of pembrolizumab combined with anlotinib suggests that the combined treatment of pembrolizumab and anlotinib might be another alternative for treating advanced NSCLC. However, due to limited number of patients enrolled in our study, large cohort clinical study is required to confirm the effect of this combination in the future.

\section{References}

Gandhi, L., Rodríguez-Abreu, D., Gadgeel, S., Esteban, E., Felip, E., De Angelis, F., Domine, M., Clingan, P., Hochmair, M. J., Powell, S. F., Cheng, S. Y., Bischoff, H. G., Peled, N., Grossi, F., Jennens, R. R., Reck, M., Hui, R., Garon, E. B., Boyer, M., Rubio-Viqueira, B., Novello, S., Kurata, T., Gray, J. E., Vida, J., Wei, Z., Yang, J., Raftopoulos, H., Pietanza, M. C., \& Garassino, M. C., \& KEYNOTE-189 Investigators. (2018). Pembrolizumab plus chemotherapy in metastatic non-smallcell lung cancer. The New England Journal of Medicine, 378(22), 20782092. http://dx.doi.org/10.1056/NEJMoa1801005. PMid:29658856.

Garber, K. (2014). Promising early results for immunotherapyantiangiogenesis combination. Journal of the National Cancer Institute, 106(11), dju392. http://dx.doi.org/10.1093/jnci/dju392. PMid:25421345.

Gibson, A. J. W., Li, H., D’Silva, A., Tudor, R. A., Elegbede, A. A., Otsuka, S. M., Bebb, D. G., \& Cheung, W. Y. (2018). Impact of number versus location of metastases on survival in stage IV M1b non-small cell lung cancer. Medical Oncology (Northwood, London, England), 35(9), 117. http://dx.doi.org/10.1007/s12032-018-1182-8. PMid:30073425.

Han, B., Li, K., Wang, Q., Zhang, L., Shi, J., Wang, Z., Cheng, Y., He, J., Shi, Y., Zhao, Y., Yu, H., Zhao, Y., Chen, W., Luo, Y., Wu, L., Wang, X., Pirker, R., Nan, K., Jin, F., Dong, J., Li, B., \& Sun, Y. (2018a). Effect of anlotinib as a third-line or further treatment on overall survival of patients with advanced non-small cell lung cancer: the ALTER 0303 phase 3 randomized clinical trial. JAMA Oncology, 4(11), 1569-1575. http://dx.doi.org/10.1001/jamaoncol.2018.3039. PMid:30098152.

Han, B., Li, K., Zhao, Y., Li, B., Cheng, Y., Zhou, J., Lu, Y., Shi, Y., Wang, Z., Jiang, L., Luo, Y., Zhang, Y., Huang, C., Li, Q., \& Wu, G. (2018b). Anlotinib as a third-line therapy in patients with refractory advanced non-small-cell lung cancer: a multicentre, randomised phase II trial (ALTER0302). British Journal of Cancer, 118(5), 654-661. http:// dx.doi.org/10.1038/bjc.2017.478. PMid:29438373.

Hanna, N. H., Schneider, B. J., Temin, S., Baker, S. Jr., Brahmer, J., Ellis, P. M., Gaspar, L. E., Haddad, R. Y., Hesketh, P. J., Jain, D., Jaiyesimi, I., Johnson, D. H., Leighl, N. B., Phillips, T., Riely, G. J., Robinson, A. G., Rosell, R., Schiller, J. H., Singh, N., Spigel, D. R., Stabler, J. O., Tashbar, J., \& Masters, G. (2020). Therapy for stage IV Non-small-cell lung cancer without driver alterations: ASCO and OH (CCO) joint guideline update. Journal of Clinical Oncology, 38(14), 1608-1632. http://dx.doi.org/10.1200/JCO.19.03022. PMid:31990617.
Herbst, R. S., Baas, P., Kim, D. W., Felip, E., Pérez-Gracia, J. L., Han, J. Y., Molina, J., Kim, J. H., Arvis, C. D., Ahn, M. J., Majem, M., Fidler, M. J., de Castro, G. Jr., Garrido, M., Lubiniecki, G. M., Shentu, Y., Im, E., Dolled-Filhart, M., \& Garon, E. B. (2016). Pembrolizumab versus docetaxel for previously treated, PD-L1-positive, advanced non-small-cell lung cancer (KEYNOTE-010): a randomised controlled trial. Lancet, 387(10027), 1540-1550. http://dx.doi.org/10.1016/ S0140-6736(15)01281-7. PMid:26712084.

Jiang, S., Liang, H., Liu, Z., Zhao, S., Liu, J., Xie, Z., Wang, W., Zhang, Y., Han, B., He, J., \& Liang, W. (2020). The impact of anlotinib on brain metastases of non-small cell lung cancer: post hoc analysis of a phase III randomized control trial (ALTER0303). The Oncologist, 25(5), e870-e874. http://dx.doi.org/10.1634/theoncologist.2019-0838. PMid:32077550.

Liang, H., \& Wang, M. (2019). Prospect of immunotherapy combined with anti-angiogenic agents in patients with advanced non-small cell lung cancer. Cancer Management and Research, 11, 7707-7719. http://dx.doi.org/10.2147/CMAR.S212238. PMid:31616186.

Lin, B., Song, X., Yang, D., Bai, D., Yao, Y., \& Lu, N. (2018). Anlotinib inhibits angiogenesis via suppressing the activation of VEGFR2, PDGFR $\beta$ and FGFR1. Gene, 654, 77-86. http://dx.doi.org/10.1016/j. gene.2018.02.026. PMid:29454091.

Mok, T. S. K., Wu, Y. L., Kudaba, I., Kowalski, D. M., Cho, B. C., Turna, H. Z., Castro, G. Jr., Srimuninnimit, V., Laktionov, K. K., Bondarenko, I., Kubota, K., Lubiniecki, G. M., Zhang, J., Kush, D., Lopes, G., Adamchuk, G., Ahn, M.-J., Alexandru, A., Altundag, O., Alyasova, A., Andrusenko, O., Aoe, K., Araujo, A., Aren, O., Arrieta Rodriguez, O., Ativitavas, T., Avendano, O., Barata, F., Barrios, C. H., Beato, C., Bergstrom, P., Betticher, D., Bolotina, L., Bondarenko, I., Botha, M., Buddu, S., Caglevic, C., Cardona, A., Castro, G. Jr., Castro, H., Cay Senler, F., Cerny, C. A. S., Cesas, A., Chan, G.-C., Chang, J., Chen, G., Chen, X., Cheng, S., Cheng, Y., Cherciu, N., Chiu, C.-H., Cho, B. C., Cicenas, S., Ciurescu, D., Cohen, G., Costa, M. A., Danchaivijitr, P., De Angelis, F., de Azevedo, S. J., Dediu, M., Deliverski, T., De Marchi, P. R. M., de The Bustamante Valles, F., Ding, Z., Doganov, B., Dreosti, L., Duarte, R., Edusma-Dy, R., Emelyanov, S., Erman, M., Fan, Y., Fein, L., Feng, J., Fenton, D., Fernandes, G., Ferreira, C., Franke, F. A., Freitas, H., Fujisaka, Y., Galindo, H., Galvez, C., Ganea, D., Gil, N., Girotto, G., Goker, E., Goksel, T., Gomez Aubin, G., Gomez Wolff, L., Griph, H., Gumus, M., Hall, J., Hart, G., Havel, L., He, J., He, Y., Hernandez Hernandez, C., Hespanhol, V., Hirashima, T., Ho, C. M. J., Horiike, A., Hosomi, Y., Hotta, K., Hou, M., How, S. H., Hsia, T.-C., Hu, Y., Ichiki, M., Imamura, F., Ivashchuk, O., Iwamoto, Y., Jaal, J., Jassem, J., Jordaan, C., Juergens, R. A., Kaen, D., Kalinka-Warzocha, E., Karaseva, N., Karaszewska, B., Kazarnowicz, A., Kasahara, K., Katakami, N., Kato, T., Kawaguchi, T., Kim, J. H., Kishi, K., Kolek, V., Koleva, M., Kolman, P., Koubkova, L., Kowalyszyn, R., Kowalski, D., Koynov, K., Ksienski, D., Kubota, K., Kudaba, I., Kurata, T., Kuusk, G., Kuzina, L., Laczo, I., Ladrera, G. E. I., Laktionov, K., Landers, G., Lazarev, S., Lerzo, G., Lesniewski Kmak, K., Li, W., Liam, C. K., Lifirenko, I., Lipatov, O., Liu, X., Liu, Z., Lo, S. H., Lopes, V., Lopez, K., Lu, S., Martinengo, G., Mas, L., Matrosova, M., Micheva, R., Milanova, Z., Miron, L., Mok, T., Molina, M., Murakami, S., Nakahara, Y., Nguyen, T. Q., Nishimura, T., Ochsenbein, A., Ohira, T., Ohman, R., Ong, C. K., Ostoros, G., Ouyang, X., Ovchinnikova, E., Ozyilkan, O., Petruzelka, L., Pham, X. D., Picon, P., Piko, B., Poltoratsky, A., Ponomarova, O., Popelkova, P., Purkalne, G., Qin, S., Ramlau, R., Rappaport, B., Rey, F., Richardet, E., Roubec, J., Ruff, P., Rusyn, A., Saka, H., Salas, J., Sandoval, M., Santos, L., Sawa, T., Seetalarom, K., Seker, M., Seki, N., Seolwane, F., Shepherd, L., Shevnya, S., Shimada, A. K., Shparyk, Y., Sinielnikov, I., Sirbu, D., Smaletz, O., Soares, J. P. H., Sookprasert, A., Speranza, G., Srimuninnimit, V., Sriuranpong, 
V., Stara, Z., Su, W.-C., Sugawara, S., Szpak, W., Takahashi, K., Takigawa, N., Tanaka, H., Tan Chun Bing, J., Tang, Q., Taranov, P., Tejada, H., Tho, L. M., Torii, Y., Trukhyn, D., Turdean, M., Turna, H., Ursol, G., Vanasek, J., Varela, M., Vallejo, M., Vera, L., Victorino, A.-P., Vlasek, T., Vynnychenko, I., Wang, B., Wang, J., Wang, K., Wu, Y., Yamada, K., Yang, C.-H., Yokoyama, T., Yokoyama, T., Yoshioka, H., Yumuk, F., Zambrano, A., Zarba, J. J., Zarubenkov, O., Zemaitis, M., Zhang, L., Zhang, L., Zhang, X., Zhao, J., Zhou, C., Zhou, J., Zhou, Q., \& Zippelius, A., \& KEYNOTE-042 Investigators. (2019). Pembrolizumab versus chemotherapy for previously untreated, PDL1-expressing, locally advanced or metastatic non-small-cell lung cancer (KEYNOTE-042): a randomised, open-label, controlled, phase 3 trial. Lancet, 393(10183), 1819-1830. http://dx.doi.org/10.1016/ S0140-6736(18)32409-7. PMid:30955977.

Ohm, J. E., \& Carbone, D. P. (2001). VEGF as a mediator of tumorassociated immunodeficiency. Immunologic Research, 23(2-3), 263-272. http://dx.doi.org/10.1385/IR:23:2-3:263. PMid:11444391.

Paz-Ares, L., Luft, A., Vicente, D., Tafreshi, A., Gümüş, M., Mazières, J., Hermes, B., Çay Şenler, F., Csőszi, T., Fülöp, A., Rodríguez-Cid, J., Wilson, J., Sugawara, S., Kato, T., Lee, K. H., Cheng, Y., Novello, S., Halmos, B., Li, X., Lubiniecki, G. M., Piperdi, B., \& Kowalski, D. M., \& KEYNOTE-407 Investigators. (2018). Pembrolizumab plus chemotherapy for squamous non-small-cell lung cancer. The New England Journal of Medicine, 379(21), 2040-2051. http://dx.doi. org/10.1056/NEJMoa1810865. PMid:30280635.

Reck, M., Rodríguez-Abreu, D., Robinson, A. G., Hui, R., Csőszi, T., Fülöp, A., Gottfried, M., Peled, N., Tafreshi, A., Cuffe, S., O’Brien, M., Rao, S., Hotta, K., Leiby, M. A., Lubiniecki, G. M., Shentu, Y., Rangwala, R., \& Brahmer, J. R., \& KEYNOTE-024 Investigators. (2016). Pembrolizumab versus Chemotherapy for PD-L1-positive non-small-cell lung cancer. The New England Journal of Medicine,
375(19), 1823-1833. http://dx.doi.org/10.1056/NEJMoa1606774. PMid:27718847.

Si, X., Zhang, L., Wang, H., Zhang, X., Wang, M., Han, B., Li, K., Wang, Q., Shi, J., Wang, Z., Cheng, Y., He, J., Shi, Y., Chen, W., Wang, X., Luo, Y., Nan, K., Jin, F., Li, B., Chen, Y., Zhou, J., \& Wang, D. (2018). Quality of life results from a randomized, double-blinded, placebo-controlled, multi-center phase III trial of anlotinib in patients with advanced non-small cell lung cancer. Lung Cancer (Amsterdam, Netherlands), 122, 32-37. http://dx.doi.org/10.1016/j. lungcan.2018.05.013. PMid:30032842.

Siegel, R. L., Miller, K. D., \& Jemal, A. (2017). Cancer statistics, 2017. CA: a Cancer Journal for Clinicians, 67(1), 7-30. http://dx.doi. org/10.3322/caac.21387. PMid:28055103.

Socinski, M. A., Jotte, R. M., Cappuzzo, F., Orlandi, F., Stroyakovskiy, D., Nogami, N., Rodríguez-Abreu, D., Moro-Sibilot, D., Thomas, C. A., Barlesi, F., Finley, G., Kelsch, C., Lee, A., Coleman, S., Deng, Y., Shen, Y., Kowanetz, M., Lopez-Chavez, A., Sandler, A., \& Reck, M., \& IMpower 150 Study Group. (2018). Atezolizumab for first-line treatment of metastatic nonsquamous NSCLC. The New England Journal of Medicine, 378(24), 2288-2301. http://dx.doi.org/10.1056/ NEJMoa1716948. PMid:29863955.

Tang, Y., Ou, Z., Yao, Z., \& Qiao, G. (2019). A case report of immune checkpoint inhibitor nivolumab combined with anti-angiogenesis agent anlotinib for advanced esophageal squamous cell carcinoma. Medicine, 98(40), e17164. http://dx.doi.org/10.1097/MD.0000000000017164. PMid:31577707.

Wu, D., Nie, J., Dai, L., Hu, W., Zhang, J., Chen, X., Ma, X., Tian, G., Han, J., Han, S., Long, J., Wang, Y., Zhang, Z., \& Fang, J. (2019). Salvage treatment with anlotinib for advanced non-small cell lung cancer. Thoracic Cancer, 10(7), 1590-1596. http://dx.doi.org/10.1111/17597714.13120. PMid:31183998. 